\title{
Enhanced Air Flow of Compost Heating System by Permanent Magnets
}

\author{
Harumi Toriyama* and Yutaka Asako \\ Department of Mechanical Engineering, Tokyo Metroplitan University, 1-1 Minami-Osawa, Hachioji, Tokyo 192-0397, \\ Japan
}

\begin{abstract}
Effect of a permanent magnet on aeration of an air duct through compost have been investigated numerically. Some compost yield heat over 60 Celsius in fermentation process. That exothermic reaction produces a considerable amount of heat, which could be a potential heating source. Fermentation reaction requires aeration, abundant supply of paramagnetic oxygen gas and exhaust of metabolized diamagnetic carbon dioxide gas. Continuous and forced air supply is more efficient rather than the conventional manual turn or stirring as aeration means.

In magneto-fluid-dynamics, the magnetizing force acting on a paramagnetic oxygen gas is applied for the enhancement of air flow, heat and mass transfer. In this research, the enhancement of the air flow of various size air ducts have been numerically investigated by applying a permanent magnet on an air duct. Numerical results shows that a permanent magnet enhances the air flow. The application of a permanent magnet to an air duct is useful for Compost Heating System (CHS), a promising alternative energy system.
\end{abstract}

Keywords: Alternative energy source, compost, aeration, magnetizing force.

\section{INTRODUCTION}

From the sustainable global development viewpoint, the following two actions are needed: The energy source transfer from fossil fuel to alternative energy source and the reduction of $\mathrm{CO}_{2}$ emission as one of causes of global warming. The remarkable alternative energy source is not only solar or wind power but also the biomass utilization. The biomass utilization requires energy transfer technology and power generation technology [1].

The first merit of compost processing is easy to produce its products. Because the compost products consist not of one specific material but of a various materials mixture. On the other hand, other energy transfer technology is inflexible and produces only one specific material.

The compost processing is the decomposition of biomass by aerobic microoganism, which live in the air or in the surface of materials by nature. Biomass is mostly made from plants and requires glycation decomposition. Direct combustion is popular energy transfer process for plants and trees utilization but inappropriate for materials with high moisture content. In addition, direct combustion emits $\mathrm{CO}_{2}$ and harmful materials $\mathrm{NO}_{\mathrm{x}}$ in the exhaust gas. Although compost process as biological transfer process is difficult to control due to its unsteadiness, it is easy to collect source materials.

The second merit is its lower maintenance cost because it does not need large-scale power plant factory. The utilization

*Address correspondence to this author at the Department of Mechanical Engineering, Tokyo Metroplitan University, 1-1 Minami-Osawa, Hachioji, Tokyo 192-0397, Japan; Tel: +81-42-677-1111(Ext. 4138);

Fax: +81-42-677-2701; E-mail: toriyama-harumi@ed.tmu.ac.jp of compost could decrease environment load and be promising as an alternative energy source.

Based on the aerobic organic decomposition reaction, aeration or turn work is indispensable for oxygen supply to maintain aerobic habitat. Continuous air supply by forced aeration increases decomposition efficiency and decreases an offensive odor rather than occasional aeration or turn work.

The running cost for aeration is a serious problem of composting, which needs aerobic environment [1, 2]. Oxygen is paramagnetic gas, which is attracted to a direction of high magnetic flux density like iron sands. So, there is a feasibility to induce air flow by using a magnet. This is the motivation of the present study to conduct numerical computations to investigate the feasibility of aeration by magnetizing force. This study is a preliminary analysis. Therefore only one set of permanent magnets is used. The magnetic field by one set of permanent magnets is not so strong. To fit such a small magnetic field scope, a duct size in this study is comparatively small. When applying to a practical usage, much more magnets would be utilized and produce much stronger magnetic field enough to induce air flow.

\section{FORMULATION}

\section{Description of the Problem}

A schematic diagram of a compost heating system is presented in Fig. (1). The composts of length $L_{C}$ are stacked vertically with a gap of $h_{C}$. The height of the inlet camber is $\mathrm{h}_{\mathrm{I}}$. A set of magnets is allocated in the composts with the distance of $h_{M}$ to yield magnetizing force that drives the air. The air flows into the inlet chamber from the left and is warmed by the composts while it passes through the gap and the warmed air flows out from the right. Because of the fric- 
tion loss on the walls, the air flow would not be induced without magnets when the inlet pressure is equal to the exit pressure. However, the air flow is induced even if the inlet pressure is equal to the exit pressure when the magnets exist. The air flow under the situation that the inlet pressure is equal to the exit pressure, will be analysed.

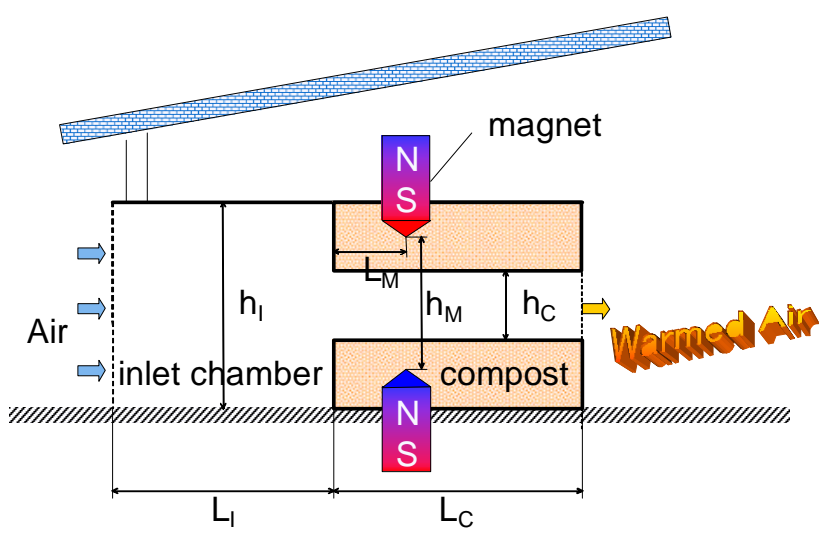

Fig. (1). Compost Heating System (CHS).

The problem is modeled as a two-dimensional air duct as shown in Fig. (2). The flow is symmetry and the flow field in the lower half area was solved. The area enclosed by dashed line is the computation domain. Note that the computation domain in the horizontal direction is expanded in both the upstream and downstream directions until the magnetizing force becomes negligible small. Neglecting the magnetizing force that works in the expanded area, the correct results are not obtained. $A B$ in the figure is the inlet boundary and the uniform inlet velocity is assumed. GH is the outflow boundary. BC and FG are boundaries of the expanded area and the slip boundary condition is applied to these boundaries. The warmed air passing through the gap between stacked composts is used as a heating source. Therefore FG boundary is regarded as an imaginary duct wall to collect the warmed air. $\mathrm{AH}$ is the symmetric boundary and the symmetric condition is applied. The governing equations for fluid flow are obtained by adding static magnetizing force term into the $\mathrm{Na}-$ vier-Stokes equations.

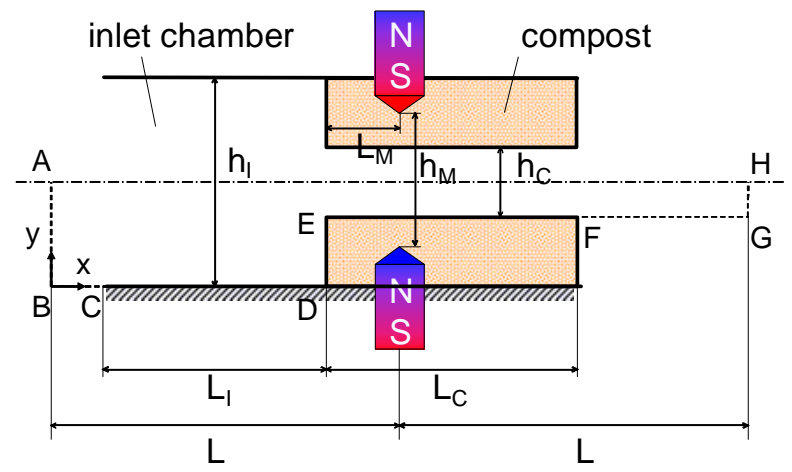

Fig. (2). Analytical Model.

In composting process, microorganism dissolves easily degradable biomass and achieves living energy through metabolism activities. Composting process is complicated systems relating tremendous microorganism. The composting process can be divided into four phases based on ambient temperature: a mesophilic phase (phase I), a thermophilic phase (phase II), a cooling phase (phase III), and a maturation phase (phase IV). In phase I, the compost mass is at ambient temperature and may be slightly acidic. In phase II, the temperature exceeds $40 \mathrm{C}$, the mesophiles decline, and degradation is dominated by the thermophiles. Reaction I mainly occurs. As readily degradable substrates decline, heat loss exceeds metabolic heat generation and phase III, the cooling phase, is initiated. Reaction II mainly occurs. Phase IV, compost maturation, is critical to its agronomic use. An immature compost can introduce phytotoxic materials to the soil. Reaction III mainly occurs [3].

Reaction I:

$$
\begin{aligned}
C_{x} H_{y} O_{z}+(x+y / 4-z / 2) O_{2} \\
\rightarrow x C O_{2}+(y / 2) H_{2} O+\Delta H_{1}
\end{aligned}
$$

Reaction II:

$$
\begin{aligned}
& n\left(\mathrm{C}_{x} \mathrm{H}_{y} \mathrm{O}_{z}\right)+n \mathrm{NH}_{3}+(x+y / 4-z / 2-5) \mathrm{O}_{2} \\
& \rightarrow\left(\mathrm{C}_{5} \mathrm{H}_{7} \mathrm{NO}_{2}\right)+n(x-5) \mathrm{CO}_{2}+(y-4)(n / 2) \mathrm{H}_{2} \mathrm{O}+\Delta \mathrm{H}_{2}
\end{aligned}
$$

Reaction III:

$$
\begin{aligned}
\mathrm{C}_{5} \mathrm{H}_{7} \mathrm{NO}_{2} & +5 n \mathrm{O}_{2} \\
& \rightarrow 5 n \mathrm{CO}_{2}+2 n \mathrm{H}_{2} \mathrm{O}+n \mathrm{NH}_{3}+\Delta \mathrm{H}_{3}
\end{aligned}
$$

It is assumed that every oxygen molecular reacts with compost and changes into carbon dioxide in a flash, after oxygen molecular reaches the surface of compost. This is, no chemical reaction occurs except on the wall. Compost consists of three phases, gas or void space, liquid and solid phase. Oxygen in air of void space is absorbed into water around compost materials, the solid phase. Aerobic bacteria, which existing in compost materials, use the absorbed oxygen in liquid phase and practice metabolic activities and excel $\mathrm{CO}_{2}$ into the air. The small duct is an enlarged and model passage to take in oxygen and to excel $\mathrm{CO}_{2}$. Therefore the size scale of the air duct is considerably small. In our future work, compost would be regarded as an porous medium. Chemical reaction occurs actually at the surface of compost fine particles. But it is too complicated for a preliminary analysis. Therefore in this study, chemical reaction is assumed to happen along only the surface of air passage.

Glucose is chosen as a representative monosaccharide, the reaction on the surface of compost is expressed as

$\mathrm{C}_{6} \mathrm{H}_{12} \mathrm{O}_{6}+6 \mathrm{O}_{2} \rightarrow 6 \mathrm{H}_{2} \mathrm{O}+6 \mathrm{CO}_{2}+\Delta \mathrm{H}$

This reaction yields carbon dioxide of $1.38 \mathrm{~kg}$ and water vapor of $0.56 \mathrm{~kg}$ per oxygen of $1 \mathrm{~kg}$. Air contains oxygen of 23 mass\% and the rest consist of nitrogen and so on. This nitrogen has nothing to do with these reactions. Therefore constant density of air is assumed [4].

Gas is classified into paramagnetic gas or diamagnetic gas. Oxygen gas has paramagnetic property. Nitrogen, carbon dioxide, water vapor and argon gas have the diamagnetic property. The magnetic susceptibility of oxygen is positive and larger than those of other diamagnetic gases by two digits. Therefore, the magnetic force to the diamagnetic gas is negligible. The magnetizing force $\vec{f}\left[\mathrm{~N} \mathrm{~m}^{-3}\right]$ which acts on air of unit volume, can be estimated from only the mass fraction of oxygen $\xi_{\mathrm{O} 2}$ as 
$\vec{f}=\frac{1}{2 M_{P 0}} \rho \chi_{O 2} \xi_{O 2} \nabla \vec{b}^{2}$

where $\mathrm{M}_{\mathrm{P}_{0}}=4 \pi \times 10^{-7} \mathrm{H} \mathrm{m}^{-1}, \chi_{\mathrm{O} 2}=1.34 \times 10^{-6} \mathrm{~m}^{3} \mathrm{~kg}^{-1}$ [5].

The fresh air which flows into the chamber, contains oxygen of 23 mass\% and is attracted toward magnets. However, the mass fraction of oxygen continually decreases, passing through the compost gap because of the reaction. The difference of the mass fraction of oxygen in the left and right sides of the magnet causes air flow in the duct. Details will be discussed later.

Steady and laminar flow and constant properties are assumed. The governing equations for the air flow of an air duct with a permanent magnet are following [6]:

$\frac{\partial u}{\partial x}+\frac{\partial v}{\partial y}=0$

$\rho u \frac{\partial u}{\partial x}+\rho v \frac{\partial u}{\partial y}=\mu\left(\frac{\partial^{2} u}{\partial x^{2}}+\frac{\partial^{2} u}{\partial y^{2}}\right)-\frac{\partial p}{\partial x}+\frac{1}{2 M_{p_{O}}} \rho \chi_{O 2} \xi_{O 2} \frac{\partial \vec{b}^{2}}{\partial x}$

$\rho u \frac{\partial v}{\partial x}+\rho v \frac{\partial v}{\partial y}=\mu\left(\frac{\partial^{2} v}{\partial x^{2}}+\frac{\partial^{2} v}{\partial y^{2}}\right)-\frac{\partial p}{\partial y}+\frac{1}{2 M_{p_{O}}} \rho \chi_{O 2} \xi_{O 2} \frac{\partial \vec{b}^{2}}{\partial y}$

where $\rho\left[\mathrm{kg} / \mathrm{m}^{3}\right]$ and $\mu[\mathrm{Pa} \mathrm{s}]$ are density and viscosity, respectively.

$u \frac{\partial \xi_{O 2}}{\partial x}+v \frac{\partial \xi_{O 2}}{\partial y}=D\left(\frac{\partial^{2} \xi_{O 2}}{\partial x^{2}}+\frac{\partial^{2} \xi_{O 2}}{\partial y^{2}}\right)$

The boundary conditions are as follows:

$$
\begin{array}{cl}
\text { on } \mathrm{AB}: & u=u_{i n,}, v=0, \xi_{\mathrm{O} 2}=0.23 \\
\text { on } \mathrm{BC}: & \frac{\partial u}{\partial y}=0, v=0, \frac{\partial \xi_{02}}{\partial y}=0 \\
\text { on } \mathrm{CD}: & \mathrm{u}=\mathrm{v}=0, \frac{\partial \xi_{O 2}}{\partial y}=0 \\
\text { on DEF : } & \mathrm{u}=\mathrm{v}=0, \xi_{\mathrm{O} 2}=0 \\
\text { on FG }: & \frac{\partial u}{\partial y}=0, \mathrm{v}=0, \frac{\partial \xi_{O 2}}{\partial y}=0 \\
\text { on } \mathrm{GH}: & \frac{\partial u}{\partial x}=0, \frac{\partial v}{\partial x}=0, \frac{\partial \xi_{O 2}}{\partial x}=0 \\
\text { on } \mathrm{AH}: & \frac{\partial u}{\partial y}=0, \mathrm{v}=0, \frac{\partial \xi_{O 2}}{\partial y}=0
\end{array}
$$

and also

$$
p_{\text {in }}=p_{\text {out }}
$$

Note that the $u_{i n}$ is not known and its value will be obtained to satisfy Eq. (11) by an arbitrary guess-andcorrection iterative procedure.

The magnetic flux density is obtained by solving the Maxwell's equations. The governing equation for the magnetic flux density is expressed as

$\operatorname{div} \vec{b}=0$
$\vec{b}=-M_{P} \operatorname{grad} \varphi_{m}+M_{P 0} \vec{M}$

where $\mathrm{M}_{\mathrm{P}}, \mathrm{M}_{\mathrm{P} 0}, \varphi_{\mathrm{m}}$ and $\vec{M}$ are the magnetic permeability, vacuum magnetic permeability, magnetic potential and magnetization, respectively. Substituting Eq. (13) into Eq. (12), Eq. (12) becomes

$$
\operatorname{div}\left(M_{P} \operatorname{grad} \varphi_{m}\right)-\operatorname{div}\left(M_{P 0} \vec{M}\right)=0
$$

Note that the magnetization, $\vec{M}$, takes a value in the permanent magnet and zero out of the magnet. Eq. (14) was numerically solved by using a software based on the magnetic moment method.

\section{NUMERICAL PROCEDURES}

The numerical methodology to solve the flow field is based on the SIMPLE method [7]. The SIMPLE method employs the finite volume method and discretes differential equations by integration in order to satisfy the conservation law of mass and momentum. The discretized procedure of the equations is based on the power law scheme of Patankar [8], and the discretized equations are solved by using a lineby-line method. The pressure and velocity are linked by SIMPLE algorithm of Patankar [7]. The convergence criterion used in this computation was that the value of the mass flux residuals (mass flow) divided by the total mass flow in each control volume took a value under $4.0 \times 10^{-11}$. The under relaxation factors for the velocity and the pressure were set to 0.8 and 0.5 , respectively. About 600 iterations were required to obtain a converged solution for the velocity field and the mass fraction field. All computations were performed with $(402 \times 42)$ grid points. These points are distributed in a uniform manner over the solution domain.

The diffusion coefficient of oxygen, nitrogen and carbon dioxide in air are $1.78 \times 10^{-5}, 1.34 \times 10^{-5}$ and $1.37 \times 10^{-5} \mathrm{~m}^{2} \mathrm{~s}^{-1}$, respectively [5]. However, in this analysis, an identical diffusion coefficient is assumed. The value of $1.37 \times 10^{-5} \mathrm{~m}^{2} \mathrm{~s}^{-1}$, was chosen for all computations.

In the magneto-fluid-dynamics, the computation domain should be wider than the area where the magnetizing force affects on the fluid. If the computation domain is smaller than that area, the correct results will not be obtained. Fig. (3) shows the effect of the size of the computation domain on the inlet velocity, $\mathrm{u}_{\text {in }}$ for a case of $\mathrm{b}_{\mathrm{T}}=0.818 \mathrm{~T}, \mathrm{~L}_{\mathrm{I}}=0.03$, $\mathrm{L}_{\mathrm{C}}=0.05, \mathrm{~h}_{\mathrm{I}}=0.02, \mathrm{~h}_{\mathrm{C}}=0.01, \mathrm{~L}_{\mathrm{M}}=0.01$ and $\mathrm{h}_{\mathrm{M}}=0.01 \mathrm{~m}$. The inlet velocity is almost constant above $\mathrm{L}=0.2 \mathrm{~m}$. The length of the computation domain, $\mathrm{L}$, is fixed at $0.2 \mathrm{~m}$ for almost of computations. Only the exception is the case for Fig. (7).

\section{RESULTS AND DISCUSSION}

The ranges of geometrical parameters are tabulated in Table 1. The magnet is a rectangular bar of $0.03 \times 0.05 \mathrm{~m}$. The magnet is chosen in such a way that the magnetic flux density at the top of the yoke, $b_{\mathrm{T}}$, ranges from 0.266 to 0.818 $\mathrm{T}$. The magnetic flux density at the top of the yoke, $b_{\mathrm{T}}$, for the typical case is $b_{T}=0.818 \mathrm{~T}$. The computations were performed for the combination of these parameters. 


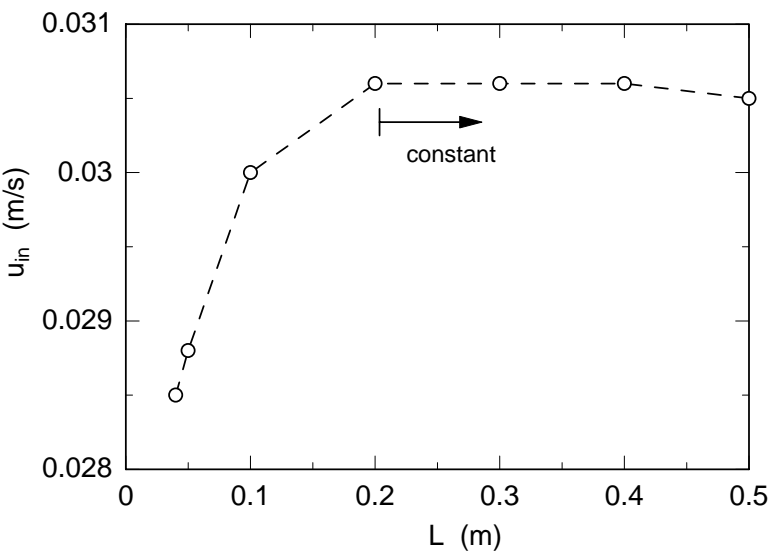

Fig. (3). Inlet velocity $u_{i n}$ as a function of $L$.

Table 1. Geometrical Parameters

\begin{tabular}{|c|c|c|}
\hline & Range[m] & Typical Length[m] \\
\hline \hline $\mathrm{L}_{\mathrm{I}}$ & $0 \sim 0.190$ & 0.03 \\
\hline $\mathrm{L}_{\mathrm{C}}$ & $0.020 \sim 0.300$ & 0.05 \\
\hline $\mathrm{h}_{\mathrm{C}}$ & $0.004 \sim 0.018$ & 0.01 \\
\hline $\mathrm{h}_{\mathrm{T}}$ & $0.005 \sim 0.030$ & 0.01 \\
\hline $\mathrm{L}_{\mathrm{M}}$ & $0.007 \sim 0.040$ & 0.01 \\
\hline $\mathrm{h}_{\mathrm{M}}$ & $0.004 \sim 0.020$ & 0.01 \\
\hline
\end{tabular}

\section{Magnetic Flux Density}

Figs. 4(a) and 4(b) show the vector plots of $\vec{b}$ and gradient of $\vec{b}^{2}$ in a lower half section of the computational domain. These are the results for $h_{M}=0.01 \mathrm{~m}$ and $b_{T}=0.818 \mathrm{~T}$. The top of lower yoke is located at the origin. It is noteworthy that all $\vec{b}$ vectors direct toward y direction and $\vec{b}$ in the area from $\mathrm{x}=-0.04$ to 0.04 takes a positive value and vectors of $\nabla \vec{b}^{2}$ in the area of $\mathrm{x}<0$ direct toward $\mathrm{x}$ direction and they in the area of $\mathrm{x}>0$ direct to $-\mathrm{x}$ direction. The vectors of $\nabla \vec{b}^{2}$ near the top of the yoke direct to the top of the yoke.

\section{Velocity Vectors, Mass Fraction \& Pressure Contours}

The computation was performed for the typical case. Fig. $\mathbf{5}$ (a) shows the velocity vectors of the flow induced by the magnets. The dot in the figure at $\mathrm{x}=0.2$ and $\mathrm{y}=0.005 \mathrm{~m}$ indicates the location of the top of the yoke. There exists a circulation near the top of the yoke. This kind of circulation can not be seen in a regular pressure driven flow.

Fig. 5(b) shows the contour of the mass fraction of oxygen. Oxygen reacts with the compost passing through the compost gap and the carbon dioxide and the water vapor are produced. The mass fraction of the oxygen deceases along the compost gap. The mass fraction at the exit of the compost takes a value of about 0.07 .

Fig. 5(c) shows the contour of the pressure. The pressure over the top of the yoke is relatively high due to the magnetizing force. Attention will now be turn to a case where no

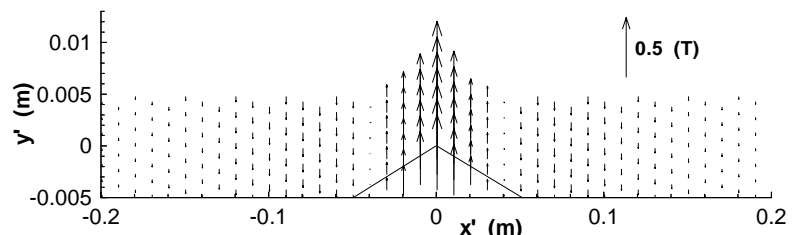

(a)

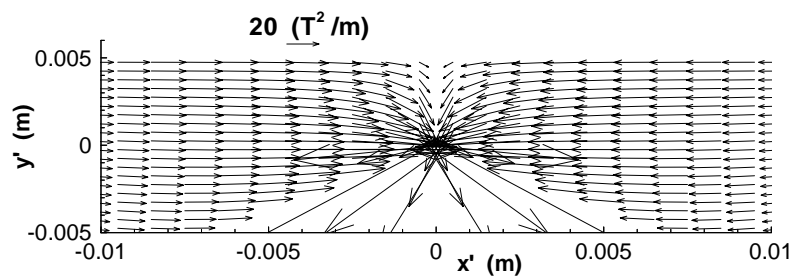

(b)

Fig. (4). Velocity plots of (a) magnetic flux density $\vec{b}$ and (b) gradient of $\vec{b}^{2}\left(\mathrm{~h}_{\mathrm{M}}=0.01 \mathrm{~m}\right.$ and $\left.\mathrm{b}_{\mathrm{T}}=0.818 \mathrm{~T}\right)$.

reaction occurs. This is, in such a case, the mass fraction of oxygen is uniform and no air flow is induced. Substituting u $=0$ into the momentum equation, Eq. (7), the equation is rewritten as.

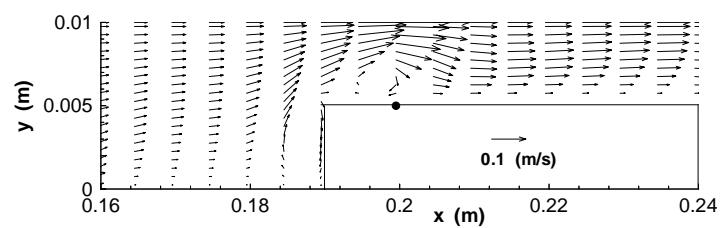

(a)

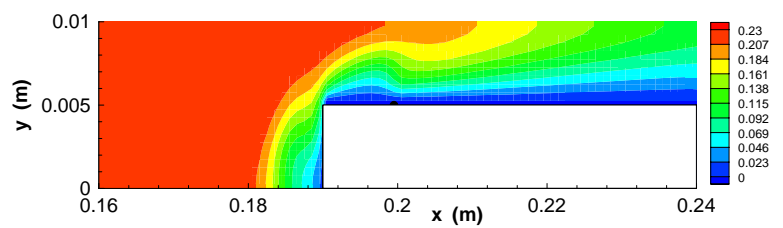

(b)

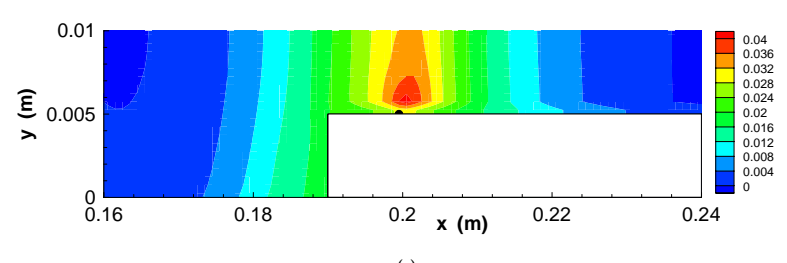

(c)

Fig. (5). (a) Velocity vectors and contour plots of (b) mass fraction of oxygen and (c) pressure for the typical case.

$\frac{\partial p}{\partial x}=\frac{1}{2 M_{P 0}} \rho \chi_{O 2} \xi_{O 2} \frac{\partial \vec{b}^{2}}{\partial x}$

The gradient of $\vec{b}^{2}$ takes a positive value in the left side area of the top of the yoke as seen in Fig. $4(\mathbf{b})$. Then, the pressure gradient takes a positive value and the pressure increases until the location of the top of the yoke and it levels off and it decreases toward the exit. This is the reason why the pressure over the top of the yoke is relatively high.

Attention will now be turn to a special case where the mass fractions of oxygen in both side areas of the yoke are 
uniform but they take different values. In such a case, the pressure at the top of the yoke calculated from the left side by using Eq. (15) differs from one calculated from the right side since the both circumstantial pressures are identical. This pressure difference induces the flow.

\section{Flow by Pressure Difference}

For information, the computation was also performed for the typical case without permanent magnets. This is, the flow is induced by the pressure difference at the inlet and the outlet. In the case of the magnet induced flow (the case of Fig. 5), the inlet velocity, $u_{\text {in }}$ is $3.06 \times 10^{-2} \mathrm{~m} \mathrm{~s}^{-1}$. To make the identical inlet velocity, the inlet pressure $p_{\text {in }}$ and the exit pressure $p_{\text {out }}$ are $-2.63 \times 10^{-9} \mathrm{~Pa}$ and $-1.01 \times 10^{-2} \mathrm{~Pa}$, respectively. The pressure difference of $1.01 \times 10^{-2} \mathrm{~Pa}$ is given. Note that $p_{\text {in }}$ and $p_{\text {out }}$ are the average pressures on $A B$ and $G H$, respectively. Fig. 6(a) shows the velocity vectors of the flow induced by the pressure difference. The circulation that is seen in Fig. 5(a) is not seen in the flow induced by the pressure difference. Fig. $\mathbf{6}(\mathbf{b})$ shows the contour of the mass fraction of oxygen. The contour of the mass fraction of oxygen is similar to one in Fig. 5(b) only the exception is one near the top of the yoke. Fig. $6(\mathbf{c})$ shows the contour of the pressure. The pressure gradually decreses along the compost gap. The magnetizing force acting on oxygen induces flow without any other external force. To induce the flow with the same velocity without permanent magnets, such a pressure difference of $1.01 \times 10^{-2} \mathrm{~Pa}$ is required by some mechanical drive.

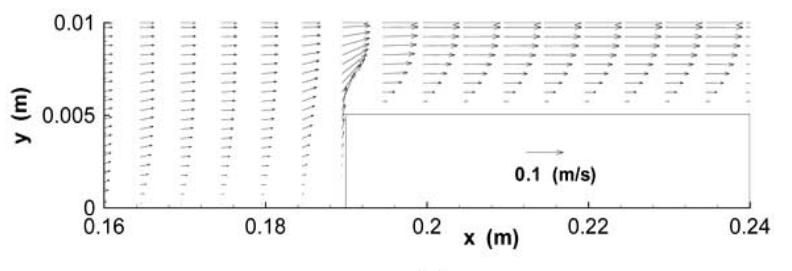

(a)

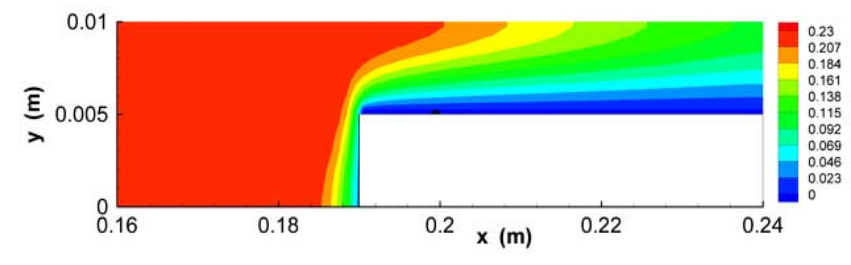

(b)

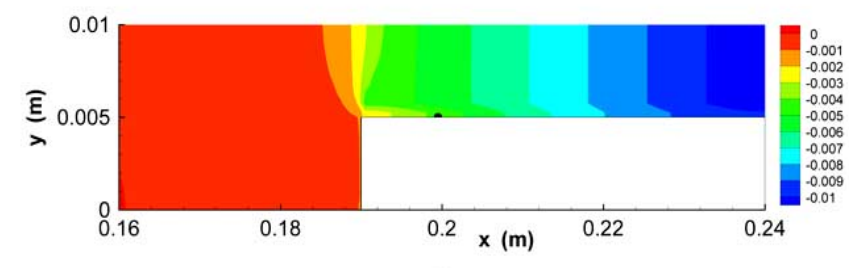

(c)

Fig. (6). (a) Velocity vectors and contour plots of (b) mass fraction of oxygen and (c) pressure for the typical case without magnets.

\section{Effect of $L_{M}$ on $u_{\text {in }}$}

The computations were also performed for the typical case except $\mathrm{L}_{\mathrm{M}}$ and $\mathrm{L}_{\mathrm{C}}$ to investigate the effect of the location of the magnet in $\mathrm{x}$ direction. The length of the compost $\mathrm{L}_{\mathrm{C}}$ is equal to $\mathrm{L}_{\mathrm{M}}+0.04$. The half length of the calculation domain, $\mathrm{L}$, of this case is not $0.2 \mathrm{~m}$ but $0.3 \mathrm{~m}$, considering the affected area of the magnet. Fig. (7) shows the effect of $\mathrm{L}_{\mathrm{M}}$ on the inlet velocity. The solid line in the figure shows the results of the computations. When the length $\mathrm{L}_{\mathrm{M}}$ becomes longer, the length of the compost $\mathrm{L}_{\mathrm{C}}$ simultaneously becomes longer. Therefore, the result includes not only the effect of the magnet location but also the friction effect due to the change in $\mathrm{L}_{\mathrm{C}}$.

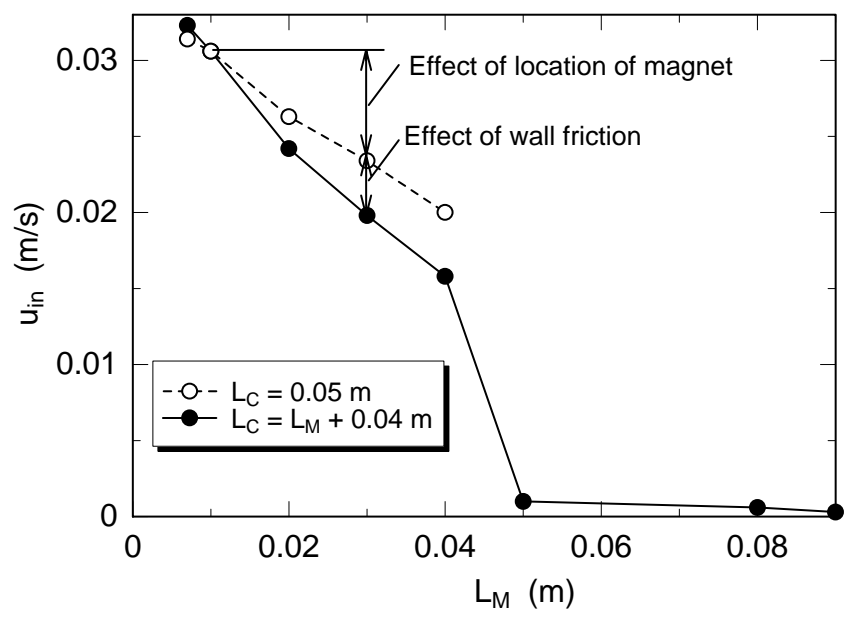

Fig. (7). $u_{\text {in }}$ as a function of $L_{M}$.

To eliminate the friction effect due to the change in $\mathrm{L}_{\mathrm{C}}$, the computations were also performed for a case that the length of the compost, $\mathrm{L}_{\mathrm{C}}$, is fixed at $0.05 \mathrm{~m}$. The dashed line in the figure shows the results for the case of $L_{C}=0.05 \mathrm{~m}$. The difference between both results represents the effect of the wall friction as shown in the figure. The maximum inlet velocity $0.0314 \mathrm{~m} / \mathrm{s}$ is obtained when the length, $L_{M}$, is 0.007 . The computation was not performed below the length $\mathrm{L}_{\mathrm{M}}=0.007 \mathrm{~m}$ because the magnets is located out of the compost.

\section{Effect of $h_{M}$ on $u_{i n}$}

The computations were performed for the typical case except $h_{M}$ to investigate the effect of gap height between the permanent magnets on the inlet velocity. Note that the gap height of the composts is fixed at $\mathrm{h}_{\mathrm{C}}=0.01 \mathrm{~m}$ and only the $\mathrm{h}_{M}$ is changed. The results are presented in Fig. (8). Although the gradient of $\vec{b}^{2}$ in $\mathrm{x}$ direction at $\mathrm{x}=0.195$ and $\mathrm{y}=$ $0.01 \mathrm{~m}$ increases with decreasing the $\mathrm{h}_{\mathrm{M}}$, it is noteworthy that the inlet velocity, $\mathrm{u}_{\mathrm{in}}$, is almost constant.

\section{Effect of Intensity of Magnet on $\mathbf{u}_{\mathrm{in}}$}

Fig. (9) shows the effect of intensity of the magnet on the inlet velocity. Seven kinds of magnets, Magnet 3000, Alnico9, SmCo18, SmCo27B, NdFeB28, NdFeB35B and Magnet 15000 were investigated. The magnetic flux densities at the top of the yoke of those magnets, $b_{\mathrm{T}}$, are 0.164 , $0.266,0.455,0.572,0.580,0.638$ and 0.818 , respectively. As expected, the inlet velocity increases approximately linearly according to the magnetic flux density at the top of the yoke, $\mathrm{b}_{\mathrm{T}}$. The results are not shown in the figure, the gradient of $\vec{b}^{2}$ is also proportional to $\mathrm{b}_{\mathrm{T}}$. Magnet 15000 has the highest value. 


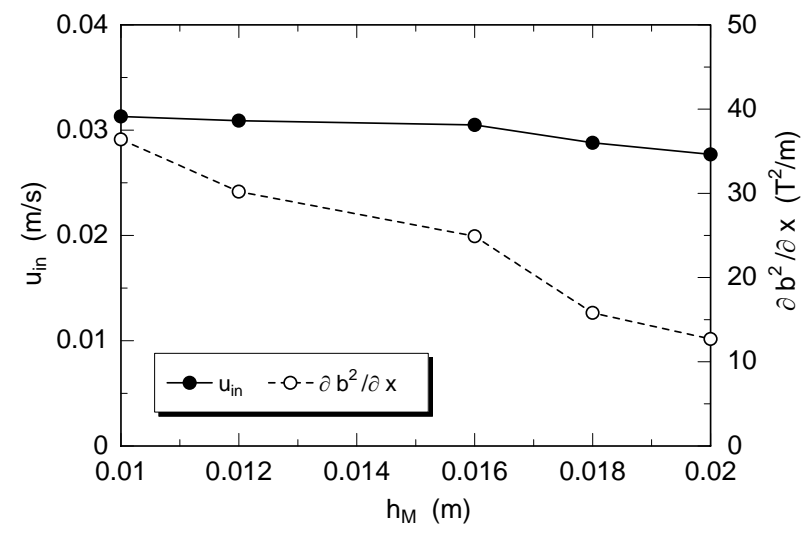

Fig. (8). $\mathrm{u}_{\text {in }}$ and $\partial b^{2} / \partial x$ as a function of $\mathrm{h}_{\mathrm{M}}$.

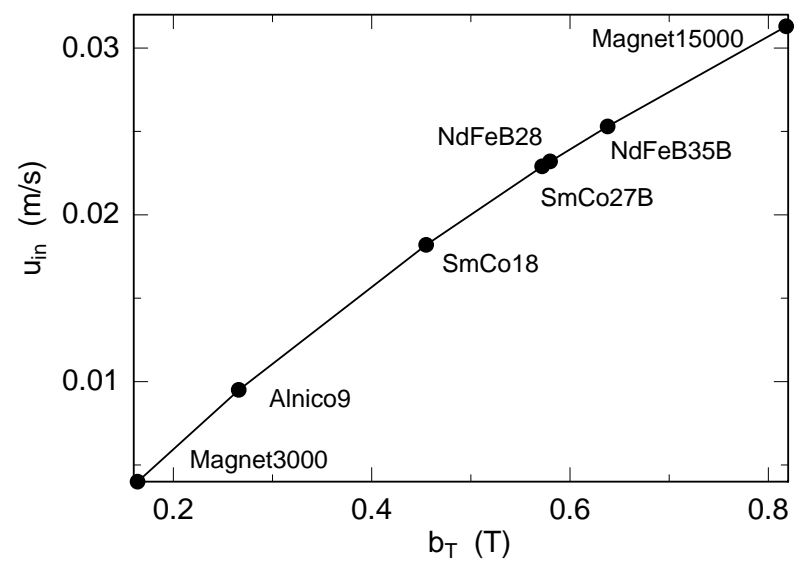

Fig. (9). $u_{\text {in }}$ as a function of surface magnetic flux density.

\section{Effect of Gap Between Composts $\mathbf{h}_{\mathrm{C}}$ on $\mathbf{u}_{\mathrm{in}}$}

The computations were also performed for the typical case except $h_{C}$ to investigate the effect of the gap between the composts on the inlet velocity. The $\mathrm{h}_{\mathrm{C}}$ ranges from 0.004 to $0.01 \mathrm{~m}$. The results are shown in Fig. (10). The inlet velocity increases in proportion to the gap between the composts because the friction loss decreases with increasing the gap height. Therefore, the larger gap is desirable.

\section{Effects of $L_{I}$ and $L_{C}$ on $u_{i n}$}

The computations were also performed for the typical case except $\mathrm{L}_{\mathrm{I}}$ to investigate the effect of the length of the inlet chamber, $\mathrm{L}_{\mathrm{I}}$ on the inlet velocity. The $\mathrm{L}_{\mathrm{I}}$ ranges from 0 to $0.19 \mathrm{~m}$. The results are shown in Fig. (11). The inlet velocity slightly decreases with increasing the $\mathrm{L}_{\mathrm{I}}$. The effect of the length of the inlet chamber on the inlet velocity is small.

The computations were also performed for the typical case except $\mathrm{L}_{\mathrm{C}}$ to investigate the effect of the length of the compost, $\mathrm{L}_{\mathrm{C}}$, on the inlet velocity. The $\mathrm{L}_{\mathrm{C}}$ ranges from 0.02 to $0.21 \mathrm{~m}$. The results are shown in Fig. (12). The inlet velocity dramatically decreases with increasing the $\mathrm{L}_{C}$, because of the friction loss. The effect of the length of the compost on the inlet velocity is relatively large. Therefore the smaller length is desirable.

\section{CONCLUSION}

Air flow though composts induced by magnets has been investigated numerically. The computations were performed

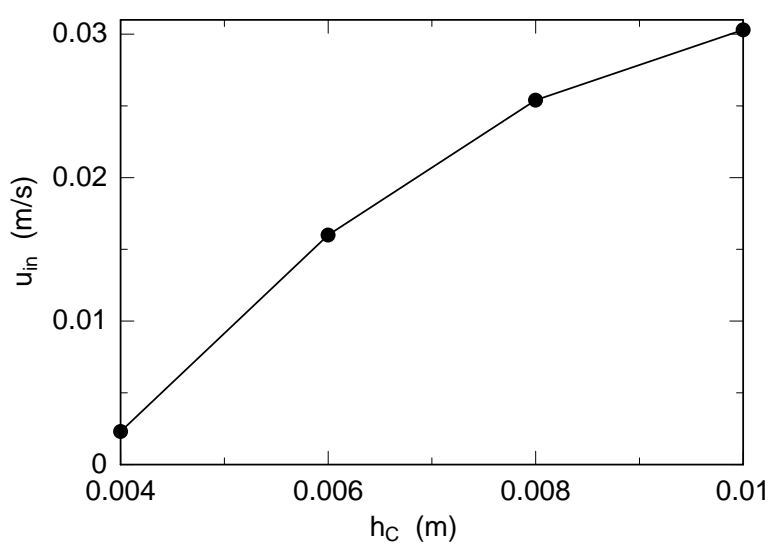

Fig. (10). $u_{\text {in }}$ as a function of $h_{C}$.

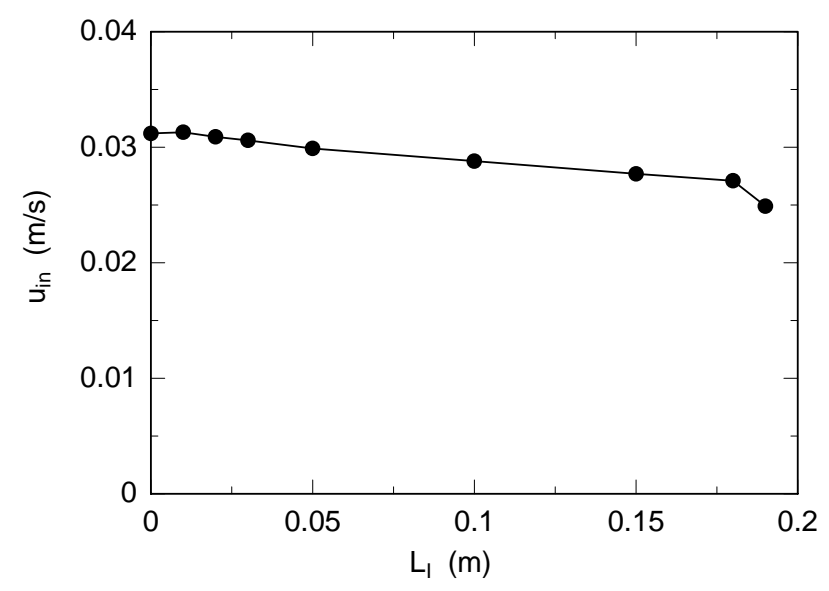

Fig. (11). $u_{\text {in }}$ as a function of $L_{I}$.

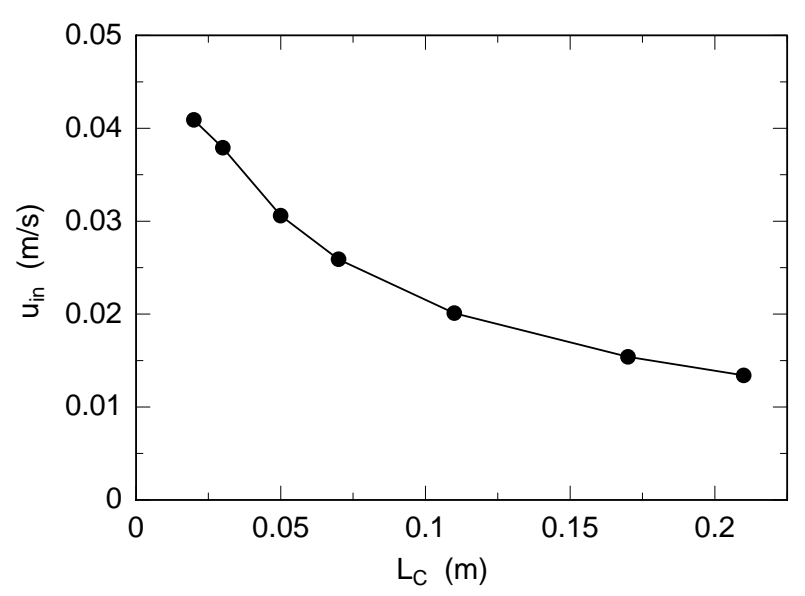

Fig. (12). $u_{\text {in }}$ as a function of $L_{C}$.

for wide range of geometric parameters. The following conclusions are obtained.

1) The utilization of magnetic force is effective to enhance air flow in compost.

2) The maximum inlet velocity $u_{i n}, 3.14 \times 10^{-2} \mathrm{~m} \mathrm{~s}^{-1}$ is obtained for the gap between the layer built compost $\mathrm{h}_{\mathrm{C}}$, $0.01 \mathrm{~m}$ and the distance between the air duct inlet and the permanent magnets, $\mathrm{L}_{\mathrm{M}}=0.007 \mathrm{~m}$. 


\section{NOMENCLATURE}

$\vec{b} \quad=$ Magnetic flux density vector $\mathrm{T}$

$\mathrm{b}_{\mathrm{T}} \quad=\vec{b}$ at top of yoke $\mathrm{T}$

$\mathrm{D}=$ Diffusion coefficient $\mathrm{m}^{2} \mathrm{~s}^{-1}$

$\mathrm{L}=$ Half length of computation domain $-\mathrm{m}$

$\mathrm{L}_{\mathrm{C}} \quad=$ Length of compost $\mathrm{m}$

$\mathrm{L}_{\mathrm{I}} \quad=$ Length of inlet chamber $\mathrm{m}$

$\mathrm{L}_{\mathrm{M}} \quad=$ Distance from edge to magnet $\mathrm{m}$

$\mathrm{f}=$ Magnetizing force per unit volume $\mathrm{N} \mathrm{m}^{-3}$

$\mathrm{M}_{\mathrm{P}} \quad=$ Magntic permeability $\mathrm{H} \mathrm{m}^{-1}$

$\mathrm{M}_{\mathrm{P} 0} \quad=$ Vacuum magnetic permeability $\mathrm{H} \mathrm{m}^{-1}$

$\mathrm{h}_{\mathrm{C}} \quad=$ Gap between composts $\mathrm{m}$

$\mathrm{h}_{\mathrm{I}} \quad=$ Height of inlet chamber $\mathrm{m}$

$\mathrm{h}_{\mathrm{M}}=$ Gap between permanent magnets $\mathrm{m}$

$\Delta \mathrm{H} \quad=$ Exothermic reaction energy $\mathrm{J} \mathrm{kg}^{-1}$

$\mathrm{i} \quad=$ Specific internal energy $\mathrm{J} \mathrm{kg}^{-1}$

$\vec{M} \quad=$ Magnetization vector

$\mathrm{p} \quad=$ Pressure $\mathrm{Pa}$

$\mathrm{u}_{\text {in }} \quad=$ Inlet velocity $\mathrm{m} \mathrm{s}^{-1}$

$\mathrm{u}, \mathrm{v}=$ Velocity components $\mathrm{m} \mathrm{s}^{-1}$ $\mathrm{x}, \mathrm{y}=$ Coordinates $\mathrm{m}$

Greek symbols

$\chi \quad=$ Magnetic susceptibility of unit mass $\mathrm{m}^{3} \mathrm{~kg}^{-1}$

$\varphi \quad=$ Magnetic potential -

$\mu \quad=$ Viscosity Pa $\mathrm{s}$

$\rho=$ Density $\mathrm{kg} \mathrm{m}^{-3}$

$\xi_{\mathrm{O} 2}=$ Mass fraction of $\mathrm{O}_{2}$ -

\section{REFERENCES}

[1] H. Yukawa, Technology of Biomass Energy, CMC Publishing CO. LTD: Tokyo, Japan, 2006. (in Japanese).

[2] T. Kimura, Composting of Biomass Resources, CMC Publishing CO., LTD: Tokyo, Japan, 2003. (in Japanese).

[3] A.C. Palmisano, and M.A. Barlaz, Microbiology of Solid Waste, CRC Press Inc.: New York, 1996.

[4] E. Klejment and M. Rosinski, "Testing of thermal properties of compost from municipal waste with a view to using it a renewable, low temperature heat source", Bioresource Technology, Vol. 99, pp.8850-8855, 2008.

[5] R.C. Weast, M.J. Astle and W.H. Beyer, CRC Handbook of Chemistry and Physics, CRC Press Inc.: New York, 1987.

[6] T. Tagawa, R. Shigematsu, and H. Ozoe, "Magnetizing force modeled and numerically solved for natural convection of air in a cubic enclosure: effect of the direction of the magnetic field", International Journal of Heat and Mass Transfer, vol. 45, pp. 267-277, 2002.

[7] S.V. Patankar, "Numerical Heat Transfer and Fluid Flow", Hemisphere Publishing Co.: Washington, D.C., 1980.

[8] S.V. Patankar, "A calculation procedure for two-dimensional elliptic situations", Numerical Heat Transfer, vol. 4, pp. 409-425, 1981.

(C) Toriyama and Asako; Licensee Bentham Open.

This is an open access article licensed under the terms of the Creative Commons Attribution Non-Commercial License (http://creativecommons.org/licenses/by-nc/3.0/) which permits unrestricted, non-commercial use, distribution and reproduction in any medium, provided the work is properly cited. 